\title{
Global Film at Global Airlines
}

\section{Dina Iordanova}

\begin{abstract}
In recent years, since the introduction of individually controlled multichannel entertainment systems on-board, it has become customary to see a growing range of international cinematic selections being made available to airline passengers. The film selection is no longer dominated by Hollywood fare; average long-haul flights now feature films sourced out of Bollywood, East Asia, and Europe, as well as from other cinematic traditions - and the selection grows in size and in variety, especially on flights that bridge together far-flung parts of the world. It is an unprecedented situation - to see global cinema "live", as it were, on board of global airlines-that turns the airlines into territories of conviviality, as no similar levels of diversity are found in the actual geographical territories of the countries where the airlines are based. Some research questions that arise in this context include: is it possible to speculate that the programme that airlines make available to audiences on long-haul flights is reflective of a specific understanding of diversity and cosmopolitanism that underwrite their choices? What message does the multifaceted and multinational entertainment menu of global airlines convey in a political context that is defined by backlash against globalisation and cosmopolitanism? Can one claim that global airlines are now one of the few platforms where global cinema is recognised and represented in its largest assortment?
\end{abstract}

\section{A "Territory" in the Air}

"When it comes to film distribution, countries and airlines appear all the same-as 'territories'." (Cousins)

The screening rights of Mark Cousins's The Story of Film: An Odyssey (2011) had sold to Finland (a country), and soon thereafter to Air Canada (an airline). Both the country and the airline had paid a fee calculated to a formula that factored in projected viewings for the film; the fee paid by the airline was larger than the fee paid by the country.

It was because of this information, which Mark Cousins shared in the conversation quoted above, that I came to think of global airlines, which showcase films on their long-haul flights, as territories. As in the cinematic culture of a country, airlines maintain a dynamic programme, showcasing a combination of new blockbusters, arthouse films, and classics. Unlike film distribution in countries however, film on global airlines reaches audiences in a different way. It is a viewing experience that is radically distinct from seeing a film in a theatre or on the big screen. The viewer is confronted with a multiple-choice film menu that is far greater and more diverse than the one available in a theatre or on television, and can compare only with the range of choice available at a film festival. Viewing takes place on small individual monitors in a darkened cabin. The film programme is included in the price, and entertainment consumption is limited only by the length of the flight.

In recent years, since the introduction of individually controlled, multichannel entertainment systems on-board, it has become customary to see a growing range of international cinematic selections being made available to passengers. For the first time, film selection does not consist mainly of Hollywood fare; the average long-haul flight features 
films sourced out of Bollywood, East Asia, and Europe, as well as from other cinematic traditions - and the selection grows in size and variety, especially on flights that bridge together far-flung parts of the world. It is this unprecedented situation - to see global cinema "live", as it were, on board of global airlines - that turns the airlines into territories of conviviality, as no similar level of diversity is found in the actual geographical territories of the countries where the airlines are based.

Hundreds of thousands of viewings take place on board of thousands of intercontinental flights every year. The film programme is included in the flight price; as no tickets are sold there are no publicly available reports on the box-office takings, and little monitoring of viewing patterns. Consequently, inflight entertainment is an understudied auxiliary film market. The fees that airlines pay for showing films are set in a way similar to selling to countries and depend on the number of projected viewers that a "territory" is expected to supply. ${ }^{1}$ From the point of view of negotiating screening rights, a "real" territory like the country Finland and a "putative" territory like the airline Air Canada are not substantially different.

Even without venturing into detailed investigation-for which I do not have sufficient information at this point-we can safely speculate that the number of films shown on the planes of a sizeable company like Turkish Airlines (c. 60 million passengers per annum; 226 international destinations to 117 countries) $)^{2}$ would probably be comparable to the film consumption of Turkey itself, a country of nearly 80 million people. And, if one looks at the sizeable Gulf companies like Emirates and Etihad (that jointly carried about 70 million passengers in 2015), one can claim that a significantly larger number of film viewings take place on board of flights than across the actual theatres of the United Arab Emirates.

Further, it is appropriate to speculate that the airlines use a composite demographic profile for their audiences, which is based on an overlap between the demographics of the respective population of the country where the company is based (relatively homogenous) and the demographics of the company's users which may not have anything to do with the base country, and are thus relatively heterogeneous. Demographically, the audience on global airlines is likely to differ from the audience found in any given country, in that it may have a more restricted range of age, income level, education, and perhaps even gender, yet a wider range of ethnic origins and linguistic capabilities. More importantly, this audience is likely to be more diverse than a national audience, more mobile, more cosmopolitan. It is likely to display more diverse and multicultural tastes.

In choosing the entertainment menu, global airlines like Avianca, Royal Air Maroc, or Aeroflot do not just mimic the tastes and interests of the population of the countries where they happen to be headquartered. Rather, they operate as a self-contained "territory", where a unique programme that brings strands of cinema that are rarely presented together to a uniquely imagined "populace", the profile of which is based on monitoring the demographics of the airline's highly mobile and cosmopolitan clientele. Some research questions that arise in this context include: Is it possible to speculate that the programme that airlines make available to audiences on long-haul flights is reflective of a specific understanding of diversity and cosmopolitanism that underwrite their choices? What message does the multifaceted and multinational entertainment menu of global airlines convey in a political context that is defined by a backlash against globalisation and cosmopolitanism? Can one claim that global airlines are now one of the few platforms where global cinema is recognised and represented in its largest assortment? 
My own thinking on these matters has been shaped, historically, in the context of working with Saskia Sassen, Arjun Appadurai and the writings of Aihwa Ong. But it is also Kwame Anthony Appiah's concept of "shared humanity", and Gerald Delanty's idea of "cosmopolitan imagination" that are of direct relevance to this investigation. It is within this framework that I will outline some specific manifestations of this conceptualisation-such as the assumptions of the cosmopolitan audience and cosmopolitan programme that airlines operate with — whilst simultaneously revealing the limitations of the discourse.

\section{"Shared Humanity" and "Cosmopolitan Imagination"}

"Inflight entertainment made cosmopolitanism - in the sense of an enthusiasm for crosscultural encounters - available to anyone on the airplane." (Groening 82)

The airlines' programming practices, all geared to catering for an imagined cosmopolitan audience, seem to be building on the notion of the "shared humanity" concept put forward by Kwame Anthony Appiah, which acknowledges that in a cosmopolitan world there will inevitably be relativism and difference, and that acceptance and dialogue are possible nonetheless. The leading principle of this worldview is predicated on the assumption that "we take seriously the value not just of human life but of particular human lives, which means taking an interest in the practices and beliefs that lend them significance" (Appiah xv). Giving exposure to international films that, supposedly, feature such "practices and beliefs" places the airlines in a proactive stance to encouraging and fostering a supranational cosmopolitan dialogue.

Gerard Delanty, another authority on cosmopolitanism, has argued in favour of a "cosmopolitan imagination" as a normative critique of globalisation's universe of multifaceted and varied enhanced connections (250-60). To him, cosmopolitanism is neither an alternative of the nation state nor a utopian ideal, but rather an embedded approach that facilitates the intercultural dialogue of borderlands and political communities in a postWestern world. Critical cosmopolitanism - the type of approach that underwrites the stance of airlines that program global cinema as inflight entertainment and thus makes a plea for intercultural dialogue - offers a solution to the challenges and shortcomings of globalisation and intercultural communication. Such views are particularly important in today's political climate, which appears to be dominated by antiglobal sentiments and crises of hospitality that started during the presidency of George Bush and are now taken further by the Trump regime.

Starting in the 1990s, a number of theorists of globalisation-Saskia Sassen, Aihwa Ong, Mike Featherstone, Zygmunt Bauman-explored the sociocultural dimensions of long distance mobility, travel, migration, and identity. Multiculturalist theorist Will Kymlicka argued that many of the world's current issues and conflicts could be put on a new footing if ethnic and national minorities were properly acknowledged, and if measures were taken to support the identity of minority cultures. Ulf Hannerz described an ever-more interconnected world where the nation-based understanding of culture has become insufficient and longdistance cultural flows were now becoming essential epistemological tools. John Urry started with a critique of the disengaged and curious "tourist gaze" (Tourist Gaze), and then took on various aspects of "mobility" (Mobilities), with concepts such as "corporeal mobility" and "imaginative travel". Manuel Castells entire oeuvre built on his view of the network society and spaces of flow, where developments in technology defined the social interaction, political, 
cultural and institutional transformation of societies around the world (Rise; Another Economy). Arjun Appadurai's overlapping crossings of "ethnoscapes", "technoscapes" and "financescapes" (which reveal themselves respectively in the specific demographics of airline passengers, the technology that makes the flight and the wealth of selective choices for online entertainment possible, and the financial set-ups that underwrite long-haul global travel) were augmented on-board by two other "scapes"-namely "mediascapes" and "ideoscapes", in that film served both a medium and a depository of ideas that need to be communicated (Appadurai 48-66). Travel writers like Pico Iyer spoke of jet lag and cultural consumption on board of long-haul flights, where endless mobility, travel and technology mutually fuel each other and where "everywhere is made up of everywhere else", all part of a multicultural journeying in search of home.

On a more sceptical note, social critic Pheng Cheah comments that the arguments of new cosmopolitanism, while focusing on the rise of transnational networks of global cities, postnational social formations created by migrant and diasporic flows, "failed to address the persistence of nationalism as a normative force within the field of uneven globalization" (290). And, indeed, in the new millennium, with the rising religious fundamentalism and massive refugee flows, there was a backlash; increasing hostility to global migrants became the norm (Sassen).

In this context, dominated by rising nationalist discourse and backlash against immigration, cosmopolitanism becomes an alternative political project of "negotiating differences". The proponent of this view, Australian theorist Nikos Papastergiadis, talks about the "kinetophobia" and "ambient fears" that take over and dictate social behaviour that imposes reduced mobility and lessened interest in other countries and peoples (19). ${ }^{3}$ This situation could be confronted by what, Papastergiadis observes, is a "conscious effort by numerous artistic and political agencies to address the empathy deficit, and close what they call the empathy gap in relation to migration and asylum issues" (Brisbourne). And, indeed, it is not only the variety of charities that are supported by the airlines (e.g. British Airways' campaign for "Flying Start"); ${ }^{4}$ the diverse line up of films found on global airlines falls in line with this view. Being, by default, global business that thrives on mobility and travel, the global airlines display a valuable variety of this "effort ... to address the empathy deficit" (Brisbourne). Inflight entertainment does tend to represent a "shared humanity" and "cosmopolitan imagination" rather than a divided world dominated by "ambient fears" (to put it all in Papastergiadis's language).

\section{Cosmopolitan Viewer Meets Cosmopolitan Programme}

\section{The Audience}

"Inflight entertainment thus exemplifies an intent to produce audiences where previously none existed.” (Groening 66)

The only detailed study that explores the history and current-day presence of cinema at global airlines, Stephen Groening's Cinema Beyond Territory extensively explores how the concept of cosmopolitanism is used by airlines in the way they approach audience and programming. Audiences for inflight entertainment are not only "produced" but also proactively imagined, in accordance with an idealised cosmopolitan notion. The perfect member of such audience is the "global nomad", a person who may originally come from 
whatever part of the world but is now living, by choice, a mobile international lifestyle (Elliott and Urry). Such person is open-minded, pluralistic and sophisticated in all personal consumer choices - be they related to food, clothes, holiday destinations, or viewing content on long-haul flights - and appreciates the abundance and diversity that a multicultural selection can offer. ${ }^{5}$

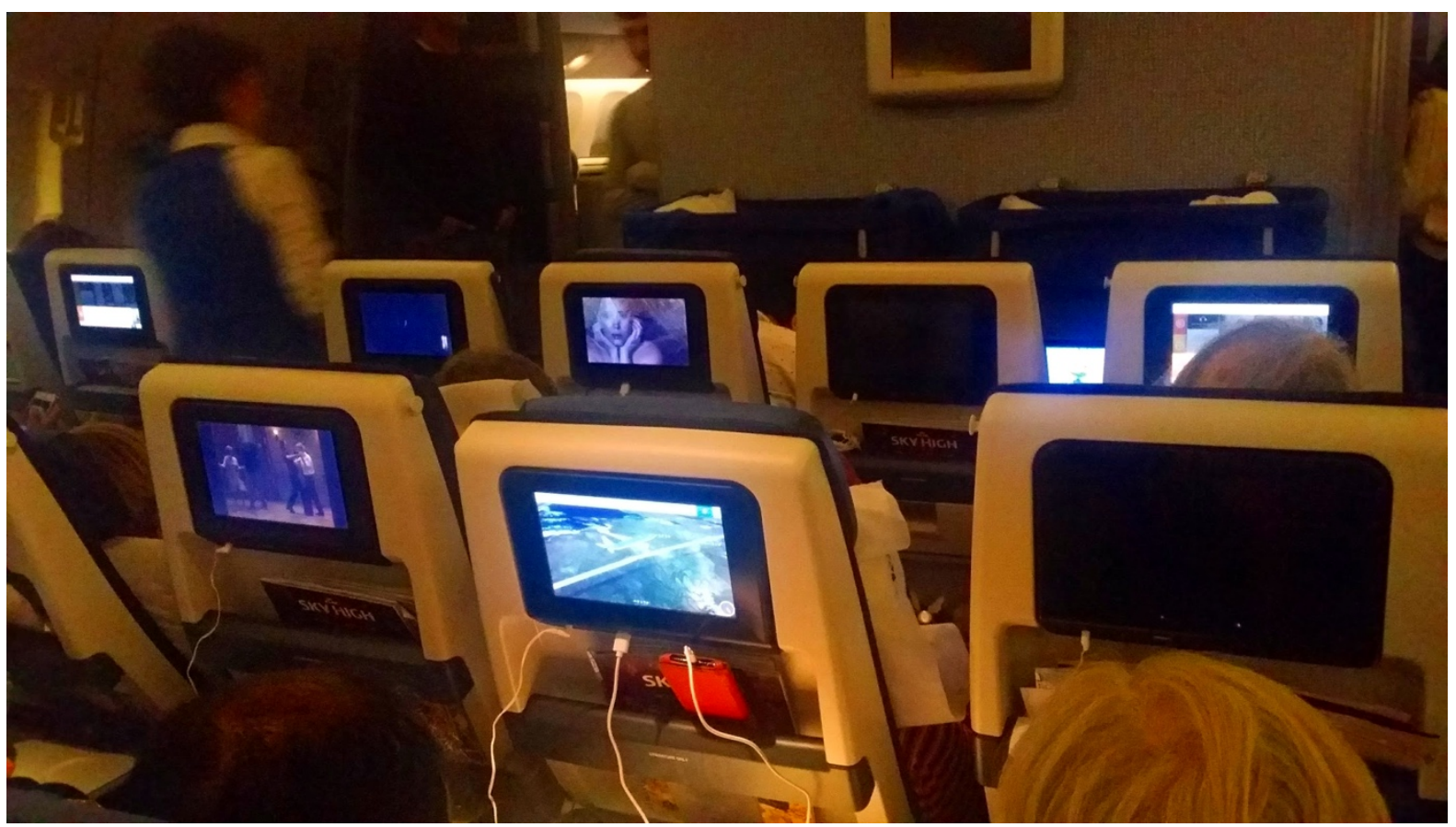

Figure 1: On-board audiences: a KLM flight to Tokyo (October 2017). Photo: Dina Iordanova.

Reflecting on the way a specific airline - namely Singapore International Airlines in 2012 - presented film menu choices on board, Groening observed that there is a clear assumption of the passengers both as international and cosmopolitan,

in that providing multiple language soundtracks and/or subtitles indicates that passengers are willing and/or eager to see films not produced in the passengers' native tongues. (54)

This becomes particularly clear from the fact that the national category is used loosely in the way menu choices are structured and is thus "a free-floating signifier within the logic of the programme" (54). He observes situations where the "airlines leverage the origin story" of certain films in view "to present a worldly and cosmopolitan menu of entertainment" (52). ${ }^{6}$

It is clear that airlines operate with a constructed image of a new cosmopolitan viewer, for whom this entertainment is designed. This is not the average short-haul flyer who crisscrosses Europe on Ryanair or EasyJet, nor the millions travelling within China-these are excluded just by virtue of the absence of inflight entertainment. ${ }^{7}$ It is the ultimate cosmopolitan viewer, a representative of the new class of global travellers-someone relatively well-educated and professional, often living in a place that is different from one's own country of birth, or one that has lived in different countries or is used to changing locations, often traveling for business (be it in business or economy class), often a person of 
higher than average exposure to cultural production originating from different regional creative hubs, and often someone fluent in more than one language.

One can observe a certain demarcation line in the specifics of the cosmopolitan viewer notion between the older, more established Western airlines and some of the new players who are based at hubs other than the oldest and most established airline centres - these later ones seem to be more innovative, broader-minded and inclusive, and thus are rewriting the rules when it comes to cinema on-board. Such companies seem to recognise more of the diverse cultural tastes and certainly appear more adventurous in their choices. ${ }^{8}$ Whilst the programme of German carrier Lufthansa, for example, revolves around mainstream Western films, with some added international sections structured around the formula "the West and the rest", 9 the pluralistic multiculturalism of the programme of LATAM Chile or Air Canada receives consistent praise from observers. ${ }^{10}$

Even where airlines keep track of the viewing that takes place on board, they do not make such information available to the companies that supply the programming content. ${ }^{11}$ But whilst programming is not done on the basis of detailed viewer preference breakdowns, it still links to a specifically constructed demographic profile of online viewership that the airlines work with. At Emirates, for example, the programming is based on two-prong matching of the passenger socio-ethnic profiles with the socio-ethnic profile of people who live in Dubai, the company's hub. One can speculate that the cultural diversity of passengers that use a company which flies to 152 different destinations is already quite substantial. As Dubai's population is characterised by a sizeable expatriate community (which by far outnumbers the local, mainly Arabic-speaking UEA citizens), ${ }^{12}$ the airline ends up featuring an international film programme, including not only Western films, but also films in the various Indian languages, as well as Filipino, Chinese, and Egyptian titles. In addition, on flights that go out to a specific destination-Denmark or Japan, for example-films from the respective country are also shown (Brannely).

\section{The Programme}

"The airline rights business is soaring as on-demand in-flight systems introduce a wider range of independent and international films to discerning passengers." (Hazelton)

In programming for inflight entertainment, global airlines do not simply assume that the specifics of the experience which renders the audience "captive" turns it into an undemanding featureless group of individuals. In spite of the captive nature of inflight viewing, global airlines persistently engage in curating their film offerings and essentially give the passengers a chance to "widen our range of experiences" (Casetti). ${ }^{13}$ Thus, the most important feature of the inflight programme is that it is curated. A closer look at a variety of elements makes it possible to see that the principles of selection and inclusion are based on the image of a globally mobile and cosmopolitan audience. ${ }^{14}$

Groening references examples where airlines have been explicit in their underscoring of the variety of choices on offer, sometimes comparing it to the wealth of offerings found at film festivals, which he regards as providing "yet another way of dividing and envisioning the world and globalized media culture" (66). Indeed, a number of airlines are known to be pairing up with film festivals and using such partnerships in promotion. ${ }^{15}$ Many airlines 
sponsor film festivals and are, in exchange, receiving reciprocal in-kind services in the areas of programming or content. ${ }^{16}$

Some have wondered if airlines have different programming between economy and business/first class. And if they do, on what assumptions are the different programming choices based? ${ }^{17}$ Are first- and business-class passengers imagined somehow as more cosmopolitan than those travelling in economy? Adrian Martin observes that such differentials seemed to be in place in the early 2000s but that it seems to have broken down more recently. ${ }^{18}$ If, however, the programming choices for First Class differ from Economy, it is a confirmation of the perception that a certain type of cinematic material is being consumed as part of behaviour that is linked to class standing and that it goes hand in hand with other elements of lifestyle choices such as the rank of hotel or rental car used. ${ }^{19}$

The politics of subtitling is another aspect that could be explored in order to see how the cosmopolitan is applied in the context of programming choices. English is invariably assumed to be the universal language. It is usually only the Hollywood films that come with subtitles in multiple languages. Films in other languages are only subtitled in English for the most part. Many more international films are listed on the menu and give an impression of variety but are not subtitled, thus restricting the audience to those who are in command of the respective (minority) language. On companies like Etihad or AirQatar, for example, one can find a number of Egyptian films, including black-and-white classics, but none of them are subtitled and it is only possible to view them if one can understand Arabic: this implies that, in the view of the programmers, it is highly unlikely that anyone from the outside would be interested in these films.

A readily available material for studying the programming is the inflight magazine, especially where it contains the film listings. However, a number of airlines have either reduced or removed these listings from the magazine and only make them available on the menus displayed on the individual screen inflight; others, like KLM, have given up on the paper magazine altogether and only make it available online or by email subscription. ${ }^{20}$ Passengers are invited to navigate the programme on the actual navigation panel of the monitors in front of them.

Generally, however, it is clear that —as is the case in many other navigable spaces, be it the IMDb or Netflix listings - the navigation categories across the majority of airlines evolve around a similar structure, following "new releases" (mainly Hollywood or Western films, with the occasional title from the airline's national cinema), "Classics", (most often Hollywood films, some fairly recent), "Bollywood" (which also includes films in other Indian languages beyond Hindi that are not normally categorised this way-Tamil, Kannada, Bengali, Mayalalam, Telugu), "Asia" (Japan, South Korea, China), "European" (a selection of recent offers from across Europe, mainly Western Europe and one or two others, usually from Russia; this is where the American indies are also included sometimes, perhaps by association with arthouse), as well as "Animation/Children/Family" (almost always American). ${ }^{21}$ The magazines often contain highlights — on British Airways, for example, the recommendations come underwritten by popular entertainer Jonathan Ross - and are thus influencing (even if not necessarily assisting) the navigation. The very choice of key categories already directs and guides the navigation.

The content that ends up online is sourced by companies which work transnationally and service a diverse range of airlines from various world regions. ${ }^{22}$ One of my informants- 
Wang Yao from the Beijing Film Academy-observed that within a month in 2016 he had travelled on three long-haul flights (Air France, Alitalia and Air China respectively), and all three conspicuously featured the same magazine "recommendation of the month" for the film Florence Foster Jenkins (Stephen Frears, 2016). This made him believe that the same international sales agent or programmer was acting behind these seemingly diverse companies, especially as they were also promoting the same films by Woody Allen (Magic in the Moonlight [2014] and Café Society [2016]).

Indeed, content sourcing companies, such as Captive Entertainment, Global Eagle, Terry Steiner International, and a range of others, negotiate screening rights as part of prerelease deals. All these companies are after what is described as an "early-window feature films", and it is a result of negotiation that "a film can now show on a plane before its international rollout and alongside a North American cinema release" (Kemp). ${ }^{23}$ Betsy Hamlin of Cinesky Pictures is known to close deals at the markets of some of the most important film festivals around the world, whilst Mister Smith Entertainment works with specific studios and independent producers. Most such companies or agents are based in Paris, London, Southern California, or New York City but are globally networked with similarly specialised outlets around the world.

Going deeper into analysing the content of the specific categories, Groening observes "a certain ambivalence towards linking the "national' to a nation state and/or language" (54). In this overall context, however, some companies develop glocal specialisms, as it were, and even promote specific local filmmaking. Air Canada seems to be shaping a reputation for an arthouse-type inflight programming: many communications have foregrounded the fact that it showcases productions of the National Film Board of Canada or compilations of shorts by Canadian filmmakers. Aer Lingus seems to enjoy a similar reputation for specialising in the promotion of Irish cinema. But even the most global of companies, like Emirates, are engaged in promotion of local filmmaking. Patrick Brannely, divisional vice president of customer experience, noted that "Emirates is very keen to show regional films, and independent films and have shown many over the years. We've also supported some directors with features in our magazines ... We recently experimented with an Arabic film by placing it in the middle of new release Hollywood films, and promoting it heavily. It had English subtitles and was a great film. Viewership was very high, and in the top 10\%" (Brannely).

\section{Global Cinema (Lives) on Board of Global Airlines}

"The new movie menu is cause for celebration in today's fraught environment for adventurous film viewing." (Ruby Rich)

The "relocation of cinema" from the cinema theatre onto multiple, variously sized and located platforms, has been gaining attention from researchers, who explore the everexpanding range of viewing opportunities and modes of access, which no longer limit it to theatrical exhibition - from large public displays in cities through to moving-image strips in the tunnels of subways (Berry, Harbord, and Moore). Cinema moving online has also been at the centre of my attention since 2012, when I worked on a study that scrutinised how cinema was reacting to the "digital disruption" (Cunningham and Iordanova), then on an essay that spoke about the transition of growing niche interest cinema material to the Internet ("Instant"), to discover, in the process of this writing, that the relocation has also a multiplicity of other manifestations. Film on airlines, specifically, has been in the centre of 
attention of Stephen Groening's comprehensive monograph, and has been touched on in cited essays by Adrian Martin and B. Ruby Rich, as well as by Francesco Casetti, who speaks of the viewing of films that takes place on board as one of cinema's new modes of existence. ${ }^{24}$ However, even in the context where not much published research exists, there is enough evidence, anecdotal or otherwise, to allow us to claim that, in the process of relocation, one of the places where cinema claims solid presence and visibility is on board of the long-haul flights of global airlines. ${ }^{25}$

It is a situation that makes global airlines a sphere of utmost importance for dissemination, as this is one of the few places where global film can manifest in all its glory and magnificent diversity. It is on global airlines where the transnational essence of cinema is fully revealed and represented, and where film can become part of a more general discourse that builds on certain humanist notions of cosmopolitanism, such as "cosmopolitics" (Cheah), "spaces of flow" (Castells, Rise), "shared humanity" (Appiah), "critical cosmopolitanism", "cosmopolitan imagination" (Delanty); and "aesthetic cosmopolitanism" (Papastergiadis).

In the real world of theatrical distribution, international cinema is represented with several strands-Hollywood, Bollywood, the East Asian and European traditions, largely speaking - that function independently from each other and interact only infrequently. It is exceptionally rare to see films from all these traditions represented together within the same space. One of the places where such coexistence takes place is on board of global airlines.

My main research interest over the years has been to uncover the (rare) instances and places where "global cinema lives" and where it all comes together in a cosmopolitan celebration of cinematic art. Such as, occasionally, on the shelves of some ethnic food shops. ${ }^{26}$ Or, more visibly, at the large international film festival and on the film festival circuit. ${ }^{27}$ Or on the Internet. ${ }^{28}$ Or in the cinemas of the city of Paris. ${ }^{29}$ And now, as I hope to have shown here, on the long-haul flights of global airlines.

Compared to previous decades - as in-flight entertainment has been around for more than fifty years - the current situation has several new features. Most airlines are now fitted with individual monitors and controls that permit the passenger to select from a wide menu of programmes, usually including feature film, television shows, documentaries, prerecorded news programmes, as well as a wealth of music choices. There is a possible parallel only to the situation that is observed on the Internet, where global film is found in places like YouTube, Vimeo, or in the context of various vaults catered for by cinephile communities and fan groups. Another parallel situation can be discovered at a reputable film festival that offers a range of diverse cinematic choices, both geographically and temporarily.

The resulting diversity is a source of excitement for film enthusiasts and researchersas exemplified by the reaction of B. Ruby Rich, who, in a preface to Film Quarterly, said she was "amazed" by what was "found on the back of the seats, in the form of the movies on offer". International airlines have become "remarkably sophisticated in the choices they provide to their passengers", she wrote. It was particularly noteworthy that "such a menu of films is an astonishing advance for US in-flight entertainment, which long offered a captive audience nothing but the most mediocre options". ${ }^{30}$ Many other, similarly enthusiastic reactions can be referenced further. ${ }^{31}$ Adrian Martin spoke of such wide selection that a cinephile would dream of being in charge of programming on long-haul plane flights. And indeed, the curated nature of in-flight entertainment results in a situation where many national cinematic traditions are properly represented and weighted in a mix that is demonstrative of 
Appiah's concept of "shared humanity". Other global providers of entertainment, such as Amazon Prime or Netflix, for example, are still remote from reaching such comprehensive diversity and representativeness.

Cinephiles who fly sufficiently frequently have already noticed the diversity and wealth of choices available on board, especially from the range of recent films that have only been released recently (or not yet released). It seems that more and more of such seasoned travellers gravitate to the stance of "catching up" during flights. I personally do it every time I go on a long-haul flight. Just in October 2016, on an outgoing British Airways flight from London to Singapore, I caught up with several films I had heard about but had not had the chance to see in cinemas or festivals - the Indian Fan (Maneesh Sharma, 2016) and the Italian A Bigger Splash (Luca Guadagnino, 2016), which had recently had a limited theatrical release in the UK, and the German Greetings from Fukushima (Grüße aus Fukushima, Doris Dorrie, 2016), which at the time of writing has not yet opened in the UK. In personal correspondence, British film scholar Tom Rice reported similar catching up done whilst on flights between Scotland and Jamaica:

I had a number of connections (three flights each way) so I flew with a combination of Delta, Air France and KLM and managed to watch eight films. It's noticeable how the airlines divide by nation/territory now and indeed I find myself watching a wider range of "world cinema" on flights (this time, including Toni Erdmann, and films from India, South Korea etc.- - finally watched I, Daniel Blake as well and, as with every flight I go on, a recent Woody Allen that I hadn't seen...).

Australian-European critic Adrian Martin reports along the same lines:

I missed the German Die Unsichtbare (Cracks in the Shell, Christian Schwochow) - a curious theatre psychodrama pitched somewhere between Black Swan and Jacques Rivette-during the International Film Festival Rotterdam. No matter: I caught it on the plane back to Australia-just one of dozens of "world movie" offerings in Economy class.

Even the founder and CEO of the IMDb, Col Needham, spoke of his habit of catching up on French and Hindi movies whilst on long-haul flights. ${ }^{32}$

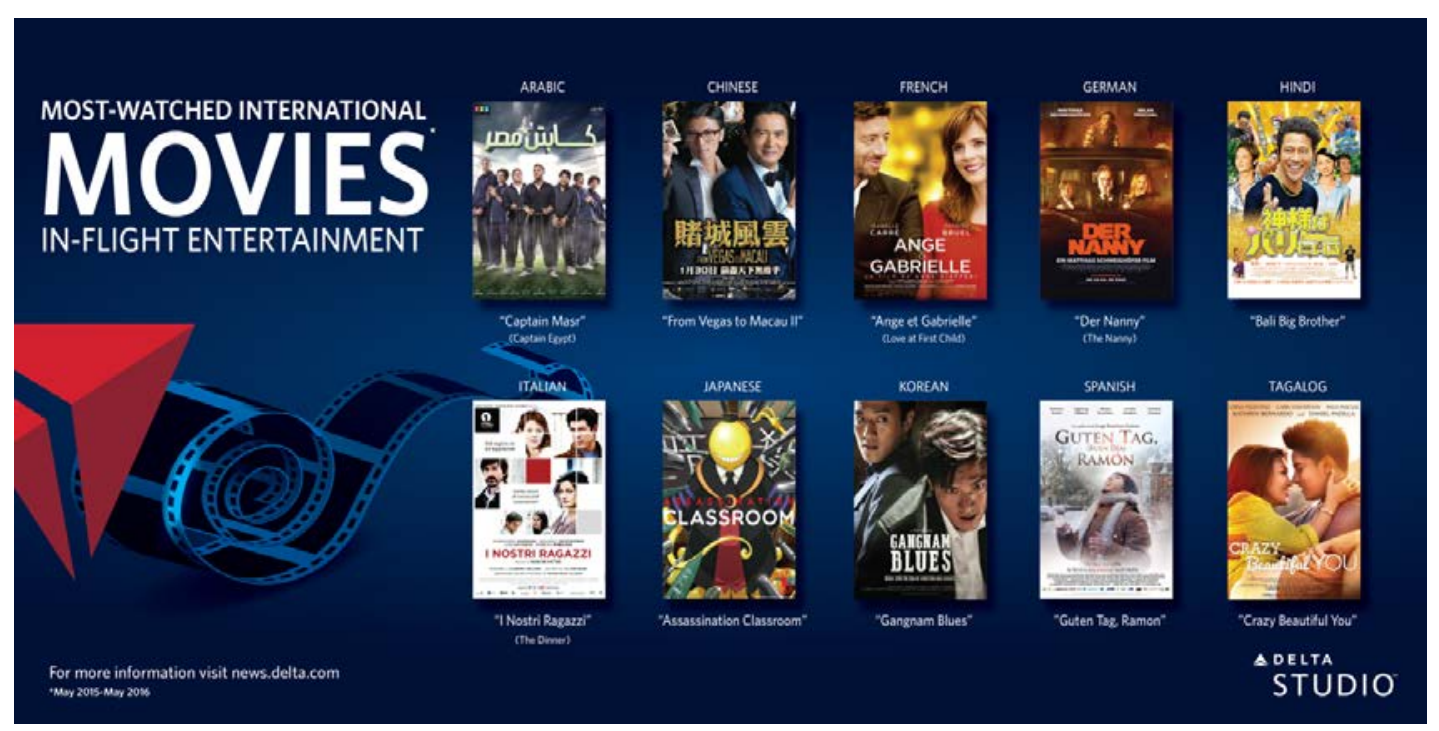

Figure 2: Top 10 international movies on Delta Studio in 2016. Image: Delta News Hub. 
In all these cases, the viewing behaviour is informed by desire to catch up-with titles that have won or have been earmarked for major awards but which one has not had the chance to see (I, Daniel Blake [Ken Loach, 2016]; Toni Erdmann [Maren Ade, 2016]), with titles that one has missed at a festival or come from a country/director/actor that one follows (Fan, Cracks in the Shell [Die Unsichtbare, Christian Schwochow, 2011]), or with titles that have extensive word-of-mouth reputations but for which one would ordinarily not make time (Game of Thrones [2011-]; The Night Manager [2016-]) —which is of importance only to people who try to stay informed about the current state of cinema. But speaking of "catching up" opens further questions for investigation. Is there a defined range of must-see titles? Apparently yes, even though it would be individual. If the catching up cuts across the board in terms of producing countries (in the current examples, the reports referred to films from Germany, India, Italy, South Korea and the UK), is there a global cinema? Apparently yes, and there is consciousness that important films are being released in all these countries, and more. And, do people want to see it? Apparently yes, if the content providers for global airlines not only recommend it but also see it as a source of "very good returns" (Kemp).

Companies based in Asia and the Middle East seem to be the ones that set and maintain the trend for diversity and cosmopolitanism in in-flight entertainment. The attention that they give to works of cinema made beyond the West is superior to the uniform and somewhat bland choices found on-board more established carriers. Companies like Cathai Pacific, Etihad, or Singapore Airlines feature ample offerings, not only of Asian (Korean, Japanese, Chinese, Thai, Indonesian) and Middle Eastern (Egyptian, Turkish) films, but also opportunities to delve into the cinemas of India beyond Bollywood, by providing access to films made in the country's other main languages, like Bengali, Tamil, Malayalam, Kannada, or Telugu. Groening observes, for example, that in 2012 the main categories on Singapore Airlines were Arabic, Asian, Chinese, English, European, Indian, Japanese and Korean, "constituting a hodgepodge of overlapping nations, regions and languages" (53). For variety and choice, Emirates is probably the leader. At any time, they feature a programme comparable in size to a mid-range film festival $(200+$ films $)$ from all over the world. ${ }^{33}$ Similar to the way in which film festivals construct their own arthouse-type audiences - by the means of catalogue entries, festival promotion trailers, and other paraphernalia - it is the cosmopolitan image that they operate that is used in decision-making and programming.

By contrast, the established Western players are lagging behind in the construction of this cosmopolitan cinema palace. On board of Air France in 2016, for example, there were no separate sections for US or French films (these were simply "cinema"), but there were defined categories for Chinese, African, Latin American, Arab, Indian, Japanese, Korean, and European films (and an "Other Countries" section listing Russian films). Whilst there was no section for French arthouse films and French cinema was mainly represented through mainstream comedies, the list had specific categories for films that had been awarded at Cannes, for shorts (featuring some Buster Keaton films), and an incoherent section on "Classical Films", including also recent films such as Titanic (James Cameron, 1997). ${ }^{34}$ The programme of British Airlines is, likewise, modestly structured around American and British titles, with a smattering of some global ones - but many of these internationals are not subtitled for English speakers.

One of the most avid and erudite cinephiles I have ever encountered was a purser, who has been working for Emirates airlines in the last eighteen years. ${ }^{35}$ This man, coming originally from a small Eastern European nation, was able to discuss recent Bollywood song and dance routines alongside vintage Korean war dramas and navigated matters on the 
representation of Cold War history on film, his special area of interest, as competently as I have seen people do at specialist conferences. And, he claimed, most of his film knowledge had come from finding breaks to watch the airline's diverse and extensive selection of films during the 12+ hour-long flights to Asia and Latin America. His random, yet substantial and longitudinal observation of people's viewing on-board was that their choices are truly diverse and that all films, no matter how obscure, do get seen.

\section{Conclusions}

The goal of this text was to pinpoint some of the specifics of the presence of global cinema on global airlines and to outline areas where further research would be beneficial for a better understanding of these processes. In conclusion, I would like to return to some of the questions that I raised at the opening of this essay.

Is the programme on long-haul flights reflective of specific concepts of diversity and cosmopolitanism that underwrite their choices? Yes, I believe it is. More concrete investigation is needed, yet the limited evidence I was able to provide here suggests that airlines have come to acknowledge the diversity of the audience for in-flight entertainment. Even if they seem to operate with a relatively elitist understanding of the cosmopolitan, the on-board programming reveals a strong tendency toward promoting the concept of "shared humanity".

What is the message behind the diversity of entertainment offering found on global airlines in a context that is defined by backlash against globalisation and cosmopolitanism? The programming approach that is observed here is suggestive of a certain political stance that may not be as articulate and defined as the one found in curatorial statements in exhibition or festival catalogues, but is, nonetheless, suggestive of a desire to address the "empathy deficit" by providing a model for a representational "shared humanity" on board.

Can one claim that global airlines are now one of the few platforms where global cinema is recognised and represented in its largest assortment? Yes, I believe I have provided evidence that indicates that the long-haul flights on global airlines are currently one of the several platforms - alongside the international film festival circuit, the rare cosmopolitan cinematic cities, and the Internet - where global cinema "lives".

\section{Acknowledgments}

I am grateful to Patrick Brannely, Mark Cousins, Jean-Michel Frodon, Aude Hesbert, Serdal Hyuseinov, Adrian Martin, Tom Rice, Leshu Torchin, Wang Yao, and Wei Lin for assistance in the preparation of this essay. Research for this article has been supported by the Carnegie Trust for the Universities of Scotland and the Leverhulme Trust, as well as by several Asian festivals which funded my long-haul flights. 


\section{Notes}

1 "Prices paid for airline rights vary on a title-by-title basis and include the size of the screen and how many long-haul flights the airline has each day, which can determine how many times the film can expect to be screened" (Kemp).

${ }^{2}$ Turkish Airlines claims to travel to 151 countries and advertises itself with the line: "We fly to more countries than any other airline in the world". The estimation I have quoted here is somewhat more modest, based on what is listed on Wikipedia - which may not be regarded as a fully trustworthy source, yet is perhaps more objective than the company's website when it comes to these matters ("Turkish").

${ }^{3}$ Both "kinetophobia" and "ambient fears" are terms specific to the work of Papastergiadis, who regards them as public reactions that develop in societies where the population is fairly mobile and where he observes oversaturation of media reports related to increased airport security, terrorist attempts, flight crashes, and in general in places where the public discourse has come to doubt the advantages of global mobility in favour of staying in one place and where anti-migration attitudes are growing in popularity.

4 "Flying Start is British Airways' global charity partnership with Comic Relief UK. The aim is to raise money to help children living incredibly tough lives in the UK and around the world. Every child deserves a Flying Start and all money raised will go to children's projects in the cities where we fly" ("Community Investment").

${ }^{5}$ I can see how the notion of this ideal/perfect audience member may come across as "elitist and idealised", as one of the two anonymous reviewers of this essay observed. S/he further questioned "whether this privileging of middle-class, educated, well-travelled individuals is the antithesis of cosmopolitan ideas." And whilst this is not the place where I am able to engage in polemics on the issue, I feel I ought to stress that my impression (based on extensive observation) is that airlines as well as many other companies that would claim to cater to a cosmopolitan audience operate precisely with such narrow and elitist concept, and I do not believe it is an "idealised" one but rather one that is based on solid marketing research related to levels of income and related economic metrics. Indeed, I have come to believe that, when it comes to the concept used by corporation, "cosmopolitanism" is probably not as socially comprehensive or as democratic as the reviewer seems to expect.

${ }^{6}$ It is interesting to observe that, even though airlines are trying to also offer a variety of food options on board (on a typical economy-class flight between Europe and Asia, for example, there would be choice of one Western and one Asian dish), they manage to do this only to a limited extent. Inflight entertainment is the only sphere where a truly rich diversity is manifested.

7 Even for such flights, however, there is expectation to find a viewing programme. Reviewing a British Airways 90-minutes-long flight from London to Frankfurt (LHR to FRA), for example, the magazine of the British Institute of Directors noted the absence of inflight entertainment and recommended that passengers "pick up a copy of Goethe's masterpiece Faust" instead (Baker 44). 
8 Some established North American airlines (Delta, American, United), where extensive business is done on long-haul flights within the same country, appear to work with a more uniform and settled image. However, even these airlines are changing in their programming, as observed by Ruby Rich.

${ }^{9}$ The programme is not particularly different from KLM, clearly showing that the choices for these are done in one go since the companies' merger in 2004.

${ }^{10}$ A global traveller, Wang Yao of the Beijing Film Academy, explicitly praised the amazing diversity of cinematic choices found on the flight that connects Chile with the Easter Island. Leshu Torchin, a colleague who fully fits in the description of the ideal global nomad viewer that airlines use to construct their audience idea, shared the following observation: "I quite dislike Air Canada for service and seats, but their inflight entertainment is brilliant for this documentary enthusiast: a full channel of National Film Board of Canada programmes that showcase documentary work and indigenous filmmakers? Wonderful. I also appreciate Aer Lingus's choice to showcase Irish filmmaking that does not receive international distribution otherwise".

11 Screen International notes in a matter-of-factly manner that detailed information on viewing practices is not available: "Airline rights are a complicated and detailed part of any film's deal memo. There is no tracking made available of viewership on a plane, so sales companies and airline distributors do not see reports on who is watching what. As a rule of thumb, airline deals mirror licensing deals struck for films in international territories" (Kemp).

12 Index Mundi lists the ethnic breakdown of Dubai in 2016 as follows: Emirati 19\%, other Arab and Iranian 23\%, South Asian 50\%, other expatriates (includes Westerners and East Asians) 8\% ("United"). Besides English and Arabic, the languages spoken in Dubai include Malayalam, Sindhi, Hindi, Tamil, Balochi, Tagalog, Persian, Urdu, Bengali and Kurdish.

${ }^{13}$ Casetti comments: "The online film forum mubi.com has hosted a debate over the course of two years about watching films on airplanes. Some of the responses are quite revealing. One user writes, 'I find the concept of watching movies on planes to be really interesting, because it's the place where you watch films that you wouldn't pick for yourself. This means that you watch some of the worst movies you've seen, but you also have a chance to watch something unexpectedly good'. On an airplane, we don't choose the film, and this is in many senses an element that distinguishes it from a movie theater; even so, this condition allows us to widen our range of experiences".

${ }^{14}$ By contrast, the programming structure of Netflix (as observed from the UK) reveals that whereas their programming structuring works with a certain general (and very different) image of an audience and its interests, the hotchpotch of titles that constitute the offer within each section reveals that no curatorial concept as such is carried through beyond the main categories.

15 According to Jenn Wint, "In celebration of its 36-year partnership with Cannes Film Festival, Air France has introduced 'Cinema to Go', which allows passengers to finish watching movies at home on their personal devices”. She also reports of United Airlines' partnership with Tribeca Film Festival which grants privileged access to some screenings to 
the MileagePlus passengers. Perhaps the only case where an airline is the creator of a film festival rather than a partner, the annual Air Canada enRoute Film Festival, established in 2007, invites novice filmmakers to submit their work for the chance to be broadcast on Air Canada international flights. Other prizes include cash and an all-inclusive trip to the 2017 Berlin International Film Festival.

16 "Supporting their homegrown filmmakers, American Airlines serves as the official airline for the Miami International Film Festival, and Emirates is a sponsor of the Dubai International Film Festival, promoting the leading film festival in the Middle East" (Wint).

17 Evidence of such differential programming is found in the partnership between United Airlines and Tribeca Film Festival where the company featured a variety of premier on-board entertainment curated by the festival in 2014 (Wint).

${ }^{18}$ Martin writes: "About a decade ago, an unexpected bump-up to Business class had me stunned when personalised service offered me a viewing of Haneke's Code Unknown (2000), while the plebs up the back (my usual spot) had to make do with mediocre Hollywood action flicks and rom-coms. But this elitism has somewhat broken down today (unless they are now watching Ken Jacobs and Lav Diaz in Business, who knows?): on my Melbourne-Rotterdam return flight, I was able to study at leisure Manoel de Oliveira's sublime The Strange Case of Angelica (2010) — which is, astonishingly, perfect plane viewing — and Kiyoshi Kurosawa's Cure (1997) which, like a previous flight's viewing of his Tokyo Sonata (2008), made me rather queasy as I hovered there above our sad, haunted planet".

19 Groening discusses the specific superior ambience of "pods" or even "suites" made available to First Class passengers on certain airlines (such as Air Nippon, Etihad, Quantas, Singapore) and implies that a significantly wider range of choices is available in this context (126). Besides the twenty-three-inch screens that he mentions as a feature of the "pods", however, there does not seem to be any evidence of differential film programming. I would speculate that whilst the viewing conditions may be better, there is no big likelihood that the featured content differs widely. (This is not the case with food choices, as it is not only the tableware but also the food that differs between the classes.)

${ }^{20}$ Thus, it is no longer possible to take along the magazine after the flight and keep track of different months editions, and explore the evolving programme month by month or comparatively between airlines - as I used to frequently do in the past. An alternative exploration may now be undertaken online.

${ }^{21}$ A sample of such typical breakdown could be explored on the website of Thai Airlines, for example ("Program").

22 "While some studios deal with content service providers such as IFE Services and Spafax - companies that select in-flight entertainment programming for groups of airlines and handle the logistics of its acquisition - others work directly with the airlines. The nature of studio deals with airlines has evolved from traditional per-flight, per-film arrangements into a mix of picture-by-picture deals, output or package deals and annual deals involving library as well as new titles" (Kemp). 
${ }^{23}$ Inflight entertainment does not seem to be part of the intricate international regulation on "windows of distribution" that are in the roots of the deepest and most profound conflicts that have been shaking the global distribution industry in the past decade. Thus, an airline can negotiate and show a film that has just been released or is not yet released in a geographical territory without being penalised by the regulators.

${ }^{24}$ Casetti's essay is first published in 2012 in Necsus. Here I am quoting from the more recent expanded version that appeared in 2017. He writes: "In 2011 it was still possible to rent a DVD in a Blockbuster shop, and already in a Redbox kiosk; spectators were able to choose a title from the catalog of Netflix or Hulu and have it in a streaming format on their TV set or on their computer; a good number of films and clips were also available on YouTube. Similarly, movies were screened on airplanes, as well as in cafés and bars, although often mingled with sports and news. The film industry itself supported these new forms of distribution" (Casetti).

25 Other similar types of places where cinema is being viewed nowadays include ferries, trains, busses, etc. "I was once extremely surprised to find Chantal Akerman's A Couch in New York both on a transatlantic flight and on a Turkish bus journey (Istanbul-Bodrum)!", one of my globe-trotting colleagues remarked in a personal exchange in 2016.

${ }^{26}$ I wrote about the video and DVD shelf nearly twenty years ago ("Expanding Universe"). At the time, cinema from other traditions mainly "lived" on the pages of the bulky Facets catalogue.

${ }^{27}$ I spent years developing scholarship on international film festivals as transnational places of cinematic encounters - and was proud to see how film festival research grew to become one of the booming strands in film studies.

${ }^{28}$ The book we dedicated to these matters of film moving online was part of a larger study, which focused on strands of global dissemination (Cunningham and Iordanova). My interest in finding the presence of nonmainstream cinema online was registered in a Cineaste piece (Iordanova, "Instant").

29 The project showcased not only specific Parisian cinemas, but was first and foremost dedicated to foregrounding the "endless film festival" found in this unique city (Frodon and Iordanova).

30 "On the way to Zurich", Rich reported, "I was able to watch Stefan Haupt's The Circle (Der Kreis), a film combining documentary and reenactments to explore gay life in Zurich's postwar period - and to slip the film into a panel discussion at the Pink Apple festival the next day. More surprisingly, en route to Provincetown for its film festival in June, I noticed my fellow flyers engrossed in Wash Westmoreland and Richard Glatzer's Still Alice, Richard Linklater's Boyhood, Xavier Dolan's Mommy, and Mike Leigh's Mr. Turner" (Rich).

${ }^{31}$ For example, there is evidence that airlines engage in growing experimentation. One of my film studies colleagues observed that whilst he traditionally deemed the documentary selection on airlines particularly poor, this was not always the case any longer. He had been on a British Airways flight that had, among the selection, "some old sponsored documentaries from the 1930s that I had written on before, so am often surprised what turns up!" (Rice). 
32 "The in-flight entertainment system was broken so no catch-ups on French/Hindi movies this time" (Needham).

${ }^{33}$ Information on the Emirates programme can be found on their website ("What's On"). The company has received a number of SkyTrax awards, which justifies its claim to be a leader in inflight entertainment.

${ }^{34}$ The picture is similar at KLM, showing that the choice of inflight entertainment is done jointly since the companies' merger in 2004.

${ }^{35}$ Serdal Hyuseinov, who I first met in April 2014, on board of an Emirates flight from Hong Kong to Dubai.

\section{References}

Appadurai, Arjun. Modernity at Large: Cultural Dimensions of Globalization. U of Minnesota P, 1996.

Appiah, Kwame Anthony. Cosmopolitanism: Ethics in a World of Strangers. Penguin, 2007.

Baker, Hannah. "Frankfurt City Guide.” Director, May 2017, pp. 43-4.

Berry, Chris, Janet Harbord, and Rachel Moore, editors. Public Space, Media Space. Palgrave Macmillan, 2013.

A Bigger Splash. Directed by Luca Guadagnino, Lucky Red, 2016.

Brannely, Patrick. Public Relations at Emirates. E-mail communication, 9 Nov. 2016.

Brisbourne, Alistair. "Interview with Professor Nikos Papastergiadis on Cosmopolitanism and Culture". Global Studies Association, GSA Newsletter, 19 Jun. 2014, globalstudiesassoc.wordpress.com/2014/06/19/interview-with-professor-nikos-papastergiadison-cosmopolitanism-and-culture.

Café Society. Directed by Woody Allen, FilmNation Entertainment, 2016.

Casetti, Francesco. "The Relocation of Cinema." Post-Cinema: Theorizing 21st-Century Film. Edited by Shane Denson and Julia Leyda, Re-frame, 2016, reframe.sussex.ac.uk/postcinema/5-1-casetti.

Castells, Manuel. Another Economy is Possible: Culture and Economy in a Time of Crisis. Polity, 2017.

---. The Rise of the Network Society: Economy, Society and Culture-Vol. 1: The Information Age: Economy, Society and Culture. Wiley-Blackwell, 2000. 
Cheah, Pheng. "Given Culture: Rethinking Cosmopolitical Freedom in Transnationalism." Boundary 2, vol. 24, no. 2, 1997, pp. 157-97.

"Community Investment." Britishairways.com, mediacentre.britishairways.com/factsheets/ details/86/Factsheets-3/6. Accessed 5 Sept. 2017.

Cousins, Mark. Personal communication, May 2014.

Cunningham, Stuart, and Dina Iordanova, editors. Digital Disruption: Cinema Moves Online. St Andrews Film Studies, 2013.

Delanty, Gerard. The Cosmopolitan Imagination: The Renewal of Critical Social Theory. Cambridge UP, 2009.

Die Unsichtbare [Cracks in the Shell]. Directed by Christian Schwochow, teamWorx Produktion, 2011.

Elliott, Anthony, and John Urry. Mobile Lives. Routledge, 2010.

Fan. Directed by Maneesh Sharma, Redchillies.VFX, 2016.

Florence Foster Jenkins. Directed by Stephen Frears, Qwerty Films, 2016.

Frodon, Jean-Michel, and Dina Iordanova, editors. Cinemas of Paris. St Andrews Film Studies, 2016.

Game of Thrones, Created by David Benioff and D. B. Weiss. HBO, 2011-2016.

Greetings from Fukushima [Grüße aus Fukushima]. Directed by Doris Dorrie, Olga Films, 2016.

Groening, Stephen. Cinema Beyond Territory: Inflight Entertainment and Atmospheres of Globalisation. BFI, 2012.

Hannerz, Ulf. Transnational Connections: Culture, People, Places. Routledge 1996.

Hazelton, John. "Up in the Air." Screen Daily, 9 Dec. 2011, www.screendaily.com/ reports/features/up-in-the-air/5035463.article.

I, Daniel Blake. Directed by Ken Loach, Sixteen Films, 2016.

Iordanova, Dina. "Expanding Universe: from the Ethnic Foodstore to Blockbuster." Framework: The Journal of Cinema and Media, vol. 41, 1999, pp. 54-70.

---. "Instant, Abundant, and Ubiquitous: Cinema Moves Online." Cineaste, vol. XXXIX, no. 1, 1994, pp. 46-51.

Iyer, Pico. The Global Soul: Jet Lag, Shopping Malls and the Search for Home. Bloomsbury, 2000. 
Kemp, Stuart. "In-Flight Entertainment: Cinemas In The Sky." Screen International, 9 May 2016, www.screendaily.com/features/in-flight-entertainment-cinemas-in-the-sky/ 5103540.article.

Kymlicka, Will. Multicultural Citizenship: A Liberal Theory of Minority Rights. Clarendon, 1996.

Magic in the Moonlight. Directed by Woody Allen, Gravier Productions, 2014.

Martin, Adrian. "In-Flight Movie.” de Filmkrant, March 2012, www.filmkrant.nl/ world_wide_angle/7732.

Needham, Col. Facebook, 26 Apr. 2017, 3:33 p.m. www.facebook.com/col.needham/posts/ 10155317455568408.

The Night Manager. Directed by Susanne Bier, The Ink Factory, 2016.

Papastergiadis, Nikos. Cosmopolitanism and Culture. Polity, 2012.

"Program." Thaiairways.com, www.thaiairways.com/en_IE/exp-my-thai/in_the_air/ program.page?. Accessed 15 May 2017.

Rice, Tom. Personal communication, 2016.

---. Personal correspondence, February 2017.

Rich, B. Ruby. "New Visions, Old Crises." Film Quarterly, vol. 69, no. 1, 23 Sept. 2015, filmquarterly.org/2015/09/23/new-visions-old-crises.

Sassen, Saskia. Guests and Aliens. The New Press, 2000.

Titanic. Directed by James Cameron, Twentieth Century Fox, 1997.

Toni Erdmann. Directed by Maren Ade, Komplizen Film, 2016.

“Turkish Airlines destinations." Wikipedia, en.wikipedia.org/wiki/Turkish_Airlines_ destinations. Accessed 15 June 2017.

Turkish Airlines. www.turkishairlines.com. Accessed 1 May 2017.

“United Arab Emirates Demographics Profile 2017." Index Mundi, 9 July 2017. www.indexmundi.com/united_arab_emirates/demographics_profile.html.

Urry, John. Mobilities, Polity. 2007.

---. The Tourist Gaze: Leisure and Travel in Contemporary Societies. Sage, 1990.

Wang Yao. Personal communication, Nov. 2016. 
"What's On.” Emirates.com, www.emirates.com/english/flying/inflight_entertainment/whatson-ice-digital-widescreen.aspx?arrAp=HKG\&depAp=DXB\&arrOr=HKG\&depOr= DXB\&UID=77WRFJY\&FINo=386\&connSeq\&fltSeq\&depDate $=170515 \&$ legSeq $=1$ $\&$ searchType $=$ ServiceFinder\&IsResultPage $=$ true $\&$ h $=16448$ b3982www.emirates.com/ engli. Accessed 5 Sept. 2017.

Wint, Jenn. "Airlines Get in on the Act With Film Festivals." APEX, 2 May 2016, apex.aero/2016/05/02/airlines-get-in-on-act-film-festivals.

\section{Suggested Citation}

Iordanova, Dina. "Global Film at Global Airlines." Alphaville: Journal of Film and Screen Media, no. 14, Winter 2017, pp. 74-93. www.alphavillejournal.com/Issue14/ArticleIordanova.pdf. ISSN: 2009-4078.

Dina Iordanova is Professor of Global Cinema at the University of St Andrews in Scotland. She is the author and editor of over fifteen books related to international cinema. 